\title{
Creating opportunities for untethered learning
}

\begin{abstract}
This paper discusses the use of mobile devices by teachers in two Australian schools. It builds on a theoretical framework which considers the location of mobile learning with respect to time and space. The research used a qualitative methodology in which observations, interviews and document analysis were conducted. The study found that the physical and virtual spaces that were used were different from those used in other lessons. Mobile learning facilitated autonomous learning by students, collaboration with their peers and engagement in topics of interest to them. The study found that students and teachers adopted new roles when using the devices, and were untethered from their conventional learning spaces of the classroom. Learning changed in nature and was aligned with contemporary practices in education.
\end{abstract}

Keywords: Mobile learning; Third Space; untethered learning; changing roles; physical and virtual spaces; changing practices

\section{Introduction and background}

The use of mobile technologies is becoming increasingly commonplace. Their use in everyday life is unprecedented (Royle, Stager \& Traxler, 2014). However, their use for learning of school-aged students is still only partially explored. Given students' increased accessibility to mobile devices, it is becoming important for teachers to be confident and competent in their ability to use such devices for teaching and for their students' learning (Cochrane \& Antonczak, 2014; Royle et al., 2014).

Mobile technologies have particular characteristics, such as connectivity and access anywhere and at any time (Norris \& Soloway, 2013). These characteristics can support learning beyond the classroom. Teachers who wish to use mobile technologies effectively for learning and teaching need to familiarise themselves with these characteristics so that they can support their students' learning in expanded environments. The project reported here examined what happened when teachers were given a mobile device and supported through facilitated action learning groups in using the devices to enhance their development of lessons. This article focuses on one aspect of the project: the changes that occurred in teaching and learning practices and subsequently in the roles of teachers and students, when they were freed or "untethered" (Traxler, 2009) from their traditional positions.

Mobile learning is learning through, or with the use of a mobile device. In this project we consider mobile devices to be those digital technologies which are easily portable, can be connected to the Internet and can be used for sharing and/or collaboration. While such a description encompasses a wide variety of devices such as laptops, phones and tablets, in this project we investigated the use of one particular device, the two-in-one device. This device comprises a small laptop, which can be seamlessly used as a tablet, by detaching the keyboard. There are two home screens, one with tablet apps on it and the other structured to offer software in the same way that a laptop would. It has the power of a laptop in terms of the software available for it, yet can be effectively used as a tablet, when app use is required.

Although there is a considerable body of research on teachers' use of technology in the classroom, most of this research has focused on either teacher learning or on online learning communities. However, there is limited research on how teaching and learning practices in schooling might change as a result of the untethering that occurs with mobile technologies. This article contributes to an understanding of the changing practices that are 
afforded by mobile technologies, by considering these changes in both online and face-toface settings. The implications for teachers' and students' roles are also explored. The research is underpinned by a theoretical framework of learning in the Third Space (Schuck, Kearney, \& Burden, 2017), a framework explicated below.

\section{Mobile learning}

A mobile-intensive pedagogy is one in which a teacher uses mobile technologies extensively to enhance teaching and learning. The 'untethering' (Traxler, 2009) of the learning from a fixed space that is provided by mobile pedagogies suggests that schools could potentially offer students opportunities for learning in spaces unbounded by the four walls of the classroom and by traditional classroom layouts that have teachers in the front of the class and students seated in set places. In an earlier paper by Schuck et al. (2017), a theoretical framework was developed using the metaphor of the Third Space, to portray the seamless learning spaces available when boundaries between formal and informal, face-to-face and virtual, synchronous and asynchronous are blurred. We describe the Third Space as the space encompassing formal and informal places and times as well as the overlaps, conduits and bridges between these places and times. Our previous work conceptualised the notion of

Third Space as follows: "an emergent shared space, providing an opportunity to develop contemporary learning skills and knowledges, a space that extends beyond traditional, institutional learning with rigid, temporal schedules to also include the spaces of more spontaneous, often incidental learning, unconstrained by classroom walls and set schedules, and sometimes free from teachers and prescribed curricula" (Schuck et al., 2017, p. 123). The 2017 article suggests that the metaphor of the Third Space could be useful in mobile learning as it highlights how the removal or blurring of traditional binaries and boundaries (Zeichner, 2010) is facilitated when mobile devices are used for learning and it provides a way of describing new learning possibilities that are offered by mobile learning untethered from the classroom. Examples of such possibilities include the learning that can occur alone or with others in informal spaces such as on trains or in coffee shops. As well, mobile learners have the potential to be freed from set timetables, due to the malleability of time afforded by instantaneous contact with others in any space and at any time (Traxler, 2009).

While this earlier paper on the Third Space (Schuck et al., 2017) discussed these opportunities in a more abstract sense, we were interested in further investigating these ideas empirically. The study discussed here explores implementation of mobile learning in two schools, and explores the Third Space concept further in these two schools.

\section{Roles of teachers and students}

Over the last few decades, there have been ongoing debates about the role of the teacher and the students in schools. Indeed, the delineation of these roles have almost become clichés: the teacher as the authoritative person, charged with transmitting information to students (the socalled "sage on the stage") as opposed to the teacher charged with providing a rich learning environment in which students construct their own knowledge and understandings (the socalled "guide on the side") (Morrison, 2014). Whether or not these role changes have actually occurred to a great extent is arguable. Ahonen, Pyhältö, Pietarinen and Soini (2014) noted that in their study, while teachers recognised the need for students to be active in their learning, they nevertheless constructed the students as passive participants, and their roles appeared to be that of transmitters of knowledge. There still appears to be a gap between teachers' espoused beliefs and their beliefs in action. 
The role of the teacher often differs in primary schools compared to secondary schools. Further, roles in secondary school classrooms often differ according to the subject being taught. In contrast to other subject areas, it is quite common for secondary school mathematics classrooms to be characterised by teachers transmitting essential information to students from the front of the classroom and then providing the students with exercises to work on. Collaborative learning communities are less frequently observed in secondary school mathematics classrooms (Gill \& Boote, 2012). In contrast, primary school teachers are increasingly building communities of learners within their classrooms and encouraging students to work collaboratively (García-Carrión \& Díez-Palomar, 2015). We use the word 'collaboration' here to describe students working together in groups, sharing goals, understandings and discussions to achieve agreed objectives (Martín del Pozo, et al., 2017).

There are a variety of ways in which teachers' roles may change as they start working with digital technologies to support technology-enhanced learning (Shaffer, Nash, \& Ruis, 2015). They may not be the central figure in interactions, as student communicate with each other and external experts online. The teacher needs to develop agency in a student-centred digital world (Kimber, Pillay \& Richards, 2002).

In addition to discussion about the changing roles of teachers and students and about current notions about transmission and construction of knowledge, there is much discussion about the need for teachers to work differently with students to develop 21 st century skills. The teaching practices of the past appear in conflict with the skills and understandings that students need today and in the future (Hung, Lee \& Lim, 2012). Much more emphasis is now given to learning that happens out of school, enabled by access to mobile technologies. Hung et al. (2012) propose that the role of the teacher is to bridge the gap between informal and formal learning.

In our previous article about the Third Space (Schuck et al., 2017), we have postulated that learning in the Third Space requires teachers and students to adopt different roles from the more traditional ones that have been present in the classroom as discussed above. To exploit the learning that takes place in informal settings, and that is self-initiated by learners, teachers need to explore different roles for themselves and their students (Schuck et al., 2017). This article builds on the conceptual work of the previous one by investigating whether and how this occurs when students and teachers implement mobile learning activities.

\section{Design of learning spaces}

There has been a recent resurgence of interest in the design of open classroom planning, in part due to the introduction of mobile devices and other educational technologies, and the affordances they might provide. In new open space schools, students can work in different environments, similarly to the ways in which many large companies operate. In these activity-based workplaces, people move from space to space and work in fluid groups depending on the task. In organisations, the use of fluid workstations has been shown to increase teamwork and provide more space for interaction and collaboration (Kim, Candido, Thomas \& de Dear, 2016).

However, many schools still operate in more traditional settings, comprising fixed classroom layouts with capacity for seating 20-35 students, screens and presentation areas placed at the front of the class and teachers' desks found at the front. Usually the way the classroom is structured tends to be aligned with the expectations of the students and teachers using that class, with respect to their different roles (Hewes, 2012). For example, a layout of desks arranged in rows facing the front usually fits with ways of teaching that acknowledge the authority of the teacher and a transmissive approach to teaching, while tables arranged 
around the classroom may indicate that collaboration is likely to be encouraged in that classroom.

Having mobile devices for student use can lead to changes in classroom and other learning settings. In school settings students can work with their devices not only in the classroom and its immediate environs but also within the school grounds. The devices' inbuilt features, such as cameras, audio recording apps and video capture provide the means to capture material for discussion and sharing (Wishart \& Triggs, 2010). Students can then collate and analyse the information on the one device (for example, place digital photos into a document) and then communicate their ideas and results with other class members and the wider community. Research indicates that students appreciate the opportunity to collect and work with the information on the one device (Maher, 2015).

This project explored what happened when teachers were provided with two-in-one devices for use with their students. The focus of this project was on the learning of the teacher and the changes that teachers experienced in their teaching and their students' learning, as a result of having access to and ownership of a two-in-one device, and access to support in using the device and accompanying apps and software in pedagogically sound ways. This article explores one particular aspect of the project, namely: What changes occurred in teaching and learning practices when the use of mobile devices untethered teachers and students from their traditional positions in the classroom? What were the implications of these changes for the roles of teachers and students?

\section{Research design}

The project was located in two government schools in New South Wales, Australia. One of the schools was a primary school (students of ages 5-12 years, grades K-6) and the other was a secondary school (students of ages 12-17, grades $7-12$ ). Both schools drew their students from relatively affluent areas. The study arose as a collaboration between university researchers, the schools and a software company that funded the research aspects of the project and also provided in-kind support in the form of the devices and technical support. The partnership is detailed in a separate paper (Maher, Schuck, \& Perry, 2017). The project had a focus on mobile learning in the discipline areas of maths and science for two reasons: firstly, this focus acknowledged the current interest in enhancing practice in STEM (science, technology, engineering and mathematics) areas; secondly, the authors are researchers in maths, science and technology and have a wealth of experience in these key learning areas.

\section{Participants}

The high school has a population of approximately 1600 students, with 77 teachers. Four teachers volunteered to be part of the project: the project initiator in the school who was part of the school leadership team (a Deputy Principal) and three mathematics teachers one of whom was also the Head of the Maths Department at the school. The Deputy Principal, while not a maths teacher, actively participated in the study and did so in her subject area of History. The three maths teachers worked collaboratively and were guided in their approaches by the Head Teacher of Maths.

The primary school has a population of approximately 750 students with 25 classroom teachers. In this school, seven teachers participated: the Deputy Principal driving technologyenhanced learning (TEL) in the school, a Deputy Principal who taught English as a second language, and five generalist primary teachers. The five teachers taught grades ranging from $\mathrm{K}$ to year 6 . Three of the participating teachers taught year three, one taught kindergarten and one teacher taught year six. Of these seven teachers, two were early career teachers with less 
than five years' teaching experience (the year 6 teacher and one of the year 3 teachers) and two had over thirty years' experience (the two Deputy Principals). All teachers at both schools who participated in the project had volunteered to do so, to develop their skills in promoting technology-enhanced learning (TEL). The three year 3 teachers worked collaboratively in this project.

\section{The study}

After support for the project was offered to the researchers by the technology company, the researchers approached the two schools and invited them to participate in the project. The schools were selected after initial contact had suggested that they both showed a great deal of interest in enhancing their TEL. Each participating teacher was provided with a two-in-one device by the partnering software company, together with technical and educational support on how to use the devices in their teaching. The university team facilitated a professional learning process, using action learning teams (Aubusson, Ewing \& Hoban, 2009), in which the teachers in each school worked as a team to develop collaborative goals for their teaching with the devices and then to implement teaching interventions, on which they collaboratively reflected and which they then amended as needed. The role of the university team was to guide the action learning and also to provide a framework (Kearney, Schuck, Burden, \& Aubusson, 2012) to scaffold the interventions enacted by the teachers. The action learning process took place over two school terms with six action learning sessions of approximately one hour each, distributed across the two terms and culminating in a final sharing of what had happened at each school in the form of a symposium to celebrate the work with school colleagues and the research team. Another aspect of the project incorporated two full-day workshops hosted by the software company and attended by the participating staff at both schools. At these workshops, sessions about how to use the device in pedagogically appropriate ways were provided. At the second workshop, all teachers shared their activities in the project with the group and there was an opportunity for discussion across primary and secondary education contexts.

A wide variety of apps/software were used by the teachers, including many apps introduced to the teachers at the two workshops. These tools included Kahoot, Office 365, Facebook, Google Drive, OneNote, OneDrive, inking feature of the Surface Pro, and a Screenbeam mirroring device.

\section{Methodology and methods}

This study was a qualitative multi-site case study, which focused on teachers' experiences. The underlying conceptual framework was interpretivist (Opie, 2004) and based on the premise that teachers' perceptions and beliefs are fundamental to the way they enact practice. The focus of this article is on how practices and roles of teachers and students might be changed by mobile learning. This aspect of the study was framed by the theoretical framework of the Third Space (Schuck et al., 2017), as a metaphor for the untethered nature of learning with mobile devices.

Data for the research project were collected in a number of ways, and were textual in most cases, with some images being collected as teachers photographed their students at work. Data collection methods included interviews with teachers at the end of the intervention, recordings of discussions occurring during action learning sessions, and collection of documents from a collaborative website documenting reflections and experiences of teachers and researchers. Other data comprised illustrative practices shared by 
the teachers in presentations to their colleagues and to the research team at the end of the project, in the form of audio recordings and presentation slides. A pre-intervention survey collected demographic details from the participants.

\section{Analysis}

Analysis was undertaken using a phenomenological lens. Of interest were the ways that the teachers were viewing the particular phenomenon of mobile learning. Descriptions of the teachers' experiences were analysed to provide insights of the factors that accounted for what was experienced or perceived to be experienced (Merriam, 1998). The data were analysed by the research team through a process of data reduction, coding and generating of categories. Analysis took place as the data were collected and often led to subsequent data being collected, as is usual in qualitative research projects (Merriam, 1998). Intra-researcher reliability was gained through having the researchers read the data and code them separately; then getting together to discuss any discrepancies in coding that might have arisen. There was strong researcher agreement about the coding and subsequent categorisation of data.

One analytic category comprised data concerning the mobility afforded by the device and the implications for practice that such mobility might have. The metaphor of the Third Space guided analysis of these data. These data concerned the untethered nature of the learning and form the basis of this paper.

\section{Limitations}

This study was small in scale and the teachers who participated in the project were all selfselected and were eager to incorporate mobile pedagogies into their learning. Therefore, the findings from this study cannot be generalised. Further, only the teachers had been provided with devices. Consequently, the examples of the students using devices that are discussed in this article arose due to students having access to the teachers' devices or to other devices, owned by the school or the student. In cases where students have less access to devices at school or at home the changes we observed might not have occurred.

\section{Findings}

The project found that the mobile feature of the devices led to some changes in practice and in roles by the teachers and subsequently by the students. In the analysis of the data, these changing practices fitted under two themes: changing practices within and beyond the classroom, and changing practices in virtual space. Other data concerned the change in roles for teachers and students engaged in the project.

Table 1 provides a summary of the changes in practices and roles according to level of class and subject area. More detailed discussion of these changes follows Table 1.

< Insert Table 1 here>

The changes summarised above are now discussed in more detail, with illustrations from the data.

\section{Changing Practices}

Changing practices within and beyond the classroom 
The teachers in the primary school were all engaged in science activities with their students in this project. In the year 3 classes taken by three of the teachers, the students were working on a project to investigate forces, motion and gravity. They were able to work in whatever area of the school they wanted to. As students could access wifi connectivity from the playground in areas near the school buildings, many groups chose to work outside in shady spots, where they could discuss their work collaboratively without the constraints of having to talk quietly and without disturbance from other groups. Other students found areas in the classrooms where they could sprawl on the carpet and collaborate with each other in a more informal setting. The students accessed the Internet to gain valuable information and also used the camera and video facilities of the devices to prepare video film reports for the teacher and for their class presentations.

Students appeared to be relaxed and motivated and clearly were enjoying working collaboratively on the task, without having to remember to talk very quietly or having to strain to hear each other above the ambient classroom noise. They also worked in ways that suited them, for example, sitting in a circle in the shade outside. While it can be argued that this type of activity frequently occurs in and out of classrooms, with or without mobile devices, what was different here was the students' access to the Internet to gain information, embed photographs from the web and from their class library into their movie reports, and to work collaboratively on a document through a collaborative writing app. Results of their science experiments were recorded using a shared online spreadsheet, which the teacher and other students could access from different physical spaces. Activities possible before mobile devices were used were enriched and expanded by their use.

One teacher explained how using mobile devices freed up the students:

I always like mobile pedagogy. I've always had children going anywhere, working anywhere. The way that my classroom operates they don't own their desk. It's who they work with, where they work, that sort of thing so it's not a structured, set formation which I find really important. ... Year 3 students really like that, sort of being able to lie on the floor and move outside, move to a quiet area if they choose to and that's with pen and paper as well but the tablet has enabled a number of things but it's not the be all and end all of mobile pedagogy. It's an assistant to it. (Year 3 Teacher: Interview)

The enabling of this movement and the ability to work in a variety of ways as described above helped the teachers conceptualise a different sort of way of conducting school and provided a conceptualisation of an expanded classroom. As one teacher explained:

So I think having mobile devices allows me to expand what the classroom looks like so that it's not just in rooms at desks and so they were working on the floor a lot more, they were working in the corridor a lot more and we were able to take our work with us a little bit more and move from room to room so they were working in the library on a collaborative doc. They could both use it in the classroom and then they could use it in the computer room so three separate rooms and they didn't even have to be in a room; they were able to take their device out. ... So I think that my idea of what a classroom should look like has altered.(Year 3 Teacher: Interview)

The project encouraged the teachers to start thinking about new spaces in which learning could take place. The project led to a re-organisation of spaces for the primary school participant teachers and their classes. The teachers saw that the students were eager to move out of the classroom to work and that they wanted spaces where they could have their 
material and displays and be able to work collaboratively and feel free from the constraints of the classroom. So the teachers set up a space in the corridors, which became the space where students could go to in their groups to work on the activities in a self-initiated way.

Many schools today are designed to incorporate corridors into their learning spaces, given that such spaces have often been found to be sites of informal learning. In this school, this occurred without design or external advice but as a result of student development of this site as a place of learning.

\section{Changing practices in the Third Space}

As noted previously, mobile devices allow students to work anywhere, anyway, anytime. This was also illustrated in the project. We have called this "changing practices in the Third Space" to acknowledge that the learning activity did not necessarily take place in the classroom during the maths lessons (in the secondary school) or during the science lessons (primary school), but could take place anywhere. One instance of working beyond the classroom was illustrated above in the first section on expanding the classroom, where students still worked in the school grounds but not necessarily in the classroom.

Another example of working in the Third Space was demonstrated by the Year 3 students as they did their homework. They were able to work collaboratively in cyberspace. They named their collaborative space the Flipheads Forum and used Google classroom to ask questions of each other out of school time, accessing the Forum from their individual homes. While engaged in their homework, students interacted in the textbox window alongside the homework, to discuss the content and suggest solutions.

Working in the Third Space also meant that students could work at any time, not just in the scheduled classroom lessons or while engaged in homework. This aspect of working any time was nicely illustrated in the secondary school, where the teacher had posed a question on order of operations to his class - Imagine you could develop your own order of operations, what would its characteristics be, and what laws would need to function? Unknown to the teacher, the students used a collaborative space he had set up for them in the cloud, to investigate and collaboratively develop a new order of operations. They did this out of school hours, and so the teacher was unaware of this thoughtful and collaborative activity until the students demonstrated their work to him at school at a later stage. This illustrated how teachers were encouraged to see students as directors of their own and each other's learning.

He described this experience:

Prime example - we were doing order of operations the other day. I gave them a homework challenge which was make up a cool order of operations - the best one I'll share on the Facebook group but they - I hadn't been in there for a couple of days and I didn't realise that they'd posted all this order of operations and they were all answering each other's and giving each other challenges and that to me, I think that they're starting to see that space as an opportunity for them to engage with each other and share their own knowledge and challenge one another and I think if you can create that environment within your classroom so it's much more student directed and that's got to have been an offshoot of allowing that flexibility with those kids.(Secondary Teacher: Interview)

Other teachers talked about how useful it was to use cloud-based technologies:

I set up the class Twitter account and we shared them [weather photographs] on a Twitter account. Showing them that the audience was actually a real thing and that we could 
interact with other schools in other places around the world gave the students a real motivation but it also gave them more language I think. If you asked them to write what they were talking about on a piece of paper, no way could we have done what we did using Twitter using the blog, using photos that we're taking and that sort of thing and making videos to explain what we're thinking because they don't have the writing skills or the reading skills ... at this point of the year. (Kindergarten Teacher: Interview)

\section{Changing role of teachers and students}

All the teachers noted that using the mobile devices stimulated them to think differently about their roles. Changes in the perceptions of their roles ranged from small, superficial changes promoted by the technology, to larger and deeper changes. An instance of a change in the first category occurred in the secondary school, where the teachers noted that not having to physically stand in front of the class to write on the board or to operate the data projector made a difference. They could operate the technology to present on the central screen while sitting at the back of the classroom. "You can't do it without the Screenbeam. If you actually have to plug yourself in then you're still tethered to the front, the whole point is lost for the way I use it." (Secondary Teacher: Interview). This led the teachers to think more about how their roles might change from that of director to that of facilitator. This fits with the literature which suggests that where the teacher is positioned in the classroom and how the furniture is arranged shapes the expectations of the students about what their respective roles will be in the lesson (Hewes, 2012).

The way in which teachers positioned themselves in the learning space was also reimagined. Teachers became more mobile in their engagement with students, which shifted the way in which they viewed their role and their ability to interact in the classroom. As stated by one secondary teacher, she was able to,

...go and sit next to a student and I've really felt that that has meant that I'm still the driver of the learning but I'm more of a passenger in terms of the discussion that has happened. It has really meant that the conversations that we have about the issues we're discussing are a little bit more free-flowing so it's good. (Secondary Teacher: Interview)

The deeper changes stimulated by the additional mobility encompassed providing the students with more opportunities to work autonomously, and to work on areas that they were particularly interested in. For example, one primary teacher stated:

...being able to use mobile devices has enabled greater collaboration and 'creativity' of students and teachers. Placed in their hands they are able to plan/design, collaborate, make, present and reflect not only on their learning as well as the "process". What worked...what didn't...skills developed...how else could we...who I work well with...what type of learner I am? and so forth... (Year 3 Teacher: Reflection)

The data showed that both teachers and students experienced a clear sense of the different possibilities that existed through the enhanced mobility enabled by using mobile devices. This ability to be untethered from the usual classroom and timetable and to operate in the Third Space (Schuck et al., 2017) provided teachers with new ways of thinking about their teaching and the learning of their students.

\section{Discussion}


We wished to investigate whether and how practices and roles of teachers and students changed when they worked with mobile devices. We used the theoretical construct of the Third Space to frame our study. The theoretical constructs developed in our earlier work on the Third Space (Schuck et al., 2017) were illustrated nicely in the examples above in the Findings Section. The contribution of this paper lies in the demonstration of how the new or expanded learning spaces led to different practices and roles in this study. We expand on this contribution below.

\section{New learning spaces}

The study demonstrated that learning in the Third Space did occur through the provision of mobile learning. This supports the suggestion by Pegrum, Oakley and Faulkner (2013) that the use of mobile devices can "lead to an expansion of the spaces and times of learning, with students learning outside the places of formal education and the hours of formal timetables ..." (p. 67). Not only can the devices allow students to work in new spaces and times, they also allow students to work in existing spaces in different ways. This article considers both the reconfiguration of existing spaces and the creation of new spaces. It is worth noting that this discussion of space is broader than the geographical notion of place. Much of the existing literature focuses on learning that occurs either in the virtual or the physical space and neglects learning in the Third Space.

The use of the devices provided opportunities for students to work within the classroom in a variety of different configurations, with some working individually, others working in small groups on the floor, or sitting in circles or working at desks. The provision of mobile devices provided opportunities for new private spaces to be created, as suggested by Mascheroni et al. (2013).

In examining how physical space was used, it became evident that existing nonteaching spaces were able to be transformed into teaching spaces. This was evidenced in the primary school where corridors, traditionally used for transporting students and storing bags, became learning spaces. This move allowed different classes to collaborate together more easily and created extra room in the classrooms which allowed them to be used in different ways. As in other research (Kim et al., 2016), we observed that students had increased opportunities to interact and collaborate with each other.

What is needed for these flexible open spaces to work effectively in schools is a revisioning of school timetabling and curriculum. Greater flexibility in timetabling and school structures would increase opportunities for students to work on tasks at times and in spaces that suit them. Such spaces would also allow for vertical integration of learning so that students can come together from different classes and year groups more easily than with a traditional timetable.

There were changes in the use of virtual spaces as well as of the physical spaces. As highlighted in the findings sections, students were able to engage with each other and with teachers in a range of online spaces. Some of these were set up by the teacher and others were student spaces that became sites of learning.

\section{Changing roles}

Teaching and learning in the Third Space also encouraged flexible teaching approaches in this study. Such approaches included more collaboration between students, encouragement of more autonomous learning by students and the opportunity to investigate areas of individual interest to the student. Teachers were also able to have more specialised roles such as technology expert, design expert or subject specialist. 
The size and mobile features of mobile devices meant that teachers were able to support learning in existing areas in new ways which impacted on the role of participants, as was discussed with the use of the screenbeam in the secondary maths classroom. The teacher was untethered from the front of the classroom, and instead was able to sit and work with the students, rather than lead them, thus allowing a more democratic discussion to take place.

Access to a virtual space also increased student autonomy and collaboration. Our data showed that there were greater opportunities for students to work collaboratively (for example, in developing their own order of operations in the virtual space) without the teacher as mediator. This process allowed the students to have a greater sense of ownership. The students were able to initiate projects independently without having a teacher drive the learning.

Students used many online resources, such as their Flipheads Forum, Facebook, Twitter and Google Sheets and gained access to external experts, which meant that the teacher's subject knowledge played a lesser role in the students' learning of maths and science. Students also became active leaders of learning by bringing online resources into the learning spaces to be shared with their peers. The democratisation of learning was clearly evident.

It was interesting to note that changes in physical learning environments occurred for the classes K-3 but year 6 and the secondary school classrooms did not take advantage of this affordance of mobile devices, tending to work either in the classroom or in virtual space. We question whether this was a result of more constraining timetables or whether the practices of teachers of earlier stages of schooling tend to be more flexible.

\section{Future Research}

Future research could centre on the nature of new schools or schools for the future. New schools with new learning spaces and ubiquitous use of mobile technologies are being designed and built. Research on the roles of teachers and students in these innovative new learning environments will provide greater insights into changing roles, practices, timetables and curriculum.

\section{Conclusions}

In this article, we suggest that spaces and teachers' roles have the potential to change radically with the use of mobile learning. The notion of the Third Space as a metaphor for the type of learning spaces that occur in mobile learning underpinned this article. Evidence was provided of new types of learning spaces, encompassing place and time. The implications of these changed learning spaces for the roles of students and teachers were indicated, but further investigation of these changes would inform our thinking about new ways of doing school.

The use of mobile devices in the classroom and beyond allows teachers to be repositioned both physically and authoritatively. Students can share their knowledge easily with the teacher and each other through contributions in online spaces. Teachers can capitalise on students' engagement with mobile devices and social media to provide students with a richer and more authentic learning experience, untethered from the four walls of the classroom, the school, the timetable and a rigid curriculum. Students are also being better prepared to play an active and comfortable role in society, working within new kinds of spaces, such as activity-based workplaces and with emerging technologies.

\section{References}


Ahonen, E., Pyhältö, K., Pietarinen, J., \& Soini, T. (2014).Teachers' professional beliefs about their roles and the pupils' roles in the school. Teacher Development, 18(2), 177197. http://dx.doi.org/10.1080/13664530.2014.900818

Aubusson, P., Ewing, R., \& Hoban, G. F. (2009).Action learning in schools: Reframing teachers' professional learning and development. Sydney: Routledge.

Cochrane, T., \& Antonczak, L. (2014).Implementing a mobile media framework for designing creative pedagogies. Social Sciences, 3(3), 359-377.

García-Carrión, R., \& Díez-Palomar, J. (2015).Learning communities: Pathways for educational success and social transformation through interactive groups in mathematics. European Educational Research Journal, 14(2), 151-166. doi:10.1177/1474904115571793

Gill, M. G., \& Boote, D. (2012). Classroom Culture, Mathematics Culture, and the Failures of Reform: The Need for a Collective View of Culture. Teachers College Record, 114(12), 1-45.

Hewes, B. (2012). Using archetypes to match learning spaces with physical and digital spaces. [online]. Metaphor, 2, pp.51-54.

Hung, D., Lee, S-S., Lim, K. (2012). Teachers as brokers: Bridging formal and informal learning in the21st century. KEDI Journal of Educational Policy, 9(1), 71-89.

Kearney, M., Schuck, S., Burden, K. \& Aubusson, P. (2012). Viewing mobile learning from a pedagogical perspective. ALT-J, Research in Learning Technology, 20(3), 1-17.

Kim, J., Candido, C., Thomas, L., \& de Dear, R. (2016). Desk ownership in the workplace: The effect of non-territorial working on employee workplace satisfaction, perceived productivity and health. Building and Environment, 103, 203-214.

Kimber, K., Pillay, H., \& Richards, C. (2002).Reclaiming teacher agency in a student-centred digital world. Asia-Pacific Journal of Teacher Education, 30(2), 155-167. doi:10.1080/13598660220135667

Maher, D. (2015). Connecting classroom and museum learning using mobile devices. Journal of Museum Education, 40(3), 257-267.

Maher, D., Schuck, S., \& Perry, R. (2017). Investigating Knowledge Exchange amongst School Teachers, University Teacher Educators and Industry Partners. Australian Journal of Teacher Education, 42(3). http://dx.doi.org/10.14221/ajte.2017v42n3.5

Mascheroni, G., Ólafsson, K., Cuman, A., Dinh, T., Haddon, L., Jørgensen, H., \& Velicu, A. (2013). Mobile internet access and use among European children: initial findings of theNet Children Go Mobile project.

http://eprints.1se.ac.uk/54244/1/Mobile\%20internet\%20access\%20and\%20use\%20amo ng\%20European\%20children_NCGM.pdf

Martín del Pozo, M., Basilotta Gómez-Pablos, V., \& García-Valcárcel Muñoz-Repiso, A. (2017). A quantitative approach to pre-service primary school teachers' attitudes towards collaborative learning with video games: previous experience with video games can make the difference. International Journal Of Educational Technology In Higher Education, 14(1), 1-18. doi:10.1186/s41239-017-0050-5

Merriam, S. (1998). Qualitative research and case study applications in education. San Francisco: Jossey-Bass.

Morrison, C. D. (2014). From 'Sage on the Stage' to 'Guide on the Side': A Good Start. International Journal for the Scholarship of Teaching and Learning, 8(1), Article 4. http://digitalcommons.georgiasouthern.edu/ij-sotl/vol8/iss1/4

Norris, C., \& Soloway, E. (2013). A conclusive thought: The opportunity to change education is, literally, at hand. In G. Trentin \& M. Repetto, (Eds.), Using network and mobile 
technology to bridge formal and informal learning (pp. 209-220). Oxford: Chandos Publishing.

Opie, C. (2004). Doing educational research. London: Sage.

Pegrum, M., Oakley, G., \& Faulkner, R. (2013). Schools going mobile: A study of the adoption of mobile handheld technologies in Western Australian independent schools. Australasian Journal of Educational Technology, 29(1), 66-81.

Royle, K., Stager, S., \& Traxler, T. (2014) Teacher development with mobiles: Comparative critical factors. Prospect, 44, 29-42.

Schuck, S., Kearney, M., \& Burden, K. (2017). Exploring mobile learning in the Third Space. Technology, Pedagogy and Education, 26(2), 121-137. http://dx.doi.org/10.1080/1475939X.2016.1230555

Shaffer, D. W., Nash, P., \& Ruis, A. R. (2015). Technology and the New Professionalization of Teaching. Teachers College Record, 117(12), 1-30.

Traxler, J. (2009). Learning in a mobile age. International Journal of Mobile and Blended Learning, 1(1), 1-12.

Wishart, J., \& Triggs, P. (2010). Museum Scouts: Exploring how schools, museums and interactive technologies can work together to support learning. Computers \& Education, 54(3), 669-678.

Zeichner, K. (2010). Rethinking the connections between campus courses and field experiences in college-and university-based teacher education. Journal of Teacher Education, 61(1-2), 89-99. 